\title{
Inferring functional brain connectivity from field- potential oscillations in health and disease
}

\author{
G Karl Steinke ${ }^{1,2}$, Roberto F Galán ${ }^{3^{*}}$ \\ From Twentieth Annual Computational Neuroscience Meeting: CNS*2011 \\ Stockholm, Sweden. 23-28 July 2011
}

Field-potential recordings (e.g. EEG, MEG) of ongoing neural activity exhibit oscillations of specific frequencies over a pink-noise 1/f background [1]. The oscillations appear in the power spectrum as a collection of frequency bands evenly spaced on a logarithmic scale, thereby preventing mutual entrainment and cross-talk.
Applying mathematical techniques for inverse problems [2], we reverse-engineered network architectures with 80 nodes that generate these characteristic dynamics of normal brain function. We show that all reconstructed networks, or "virtual brains", display similar topological features (e.g. structural motifs) and dynamics (e.g.
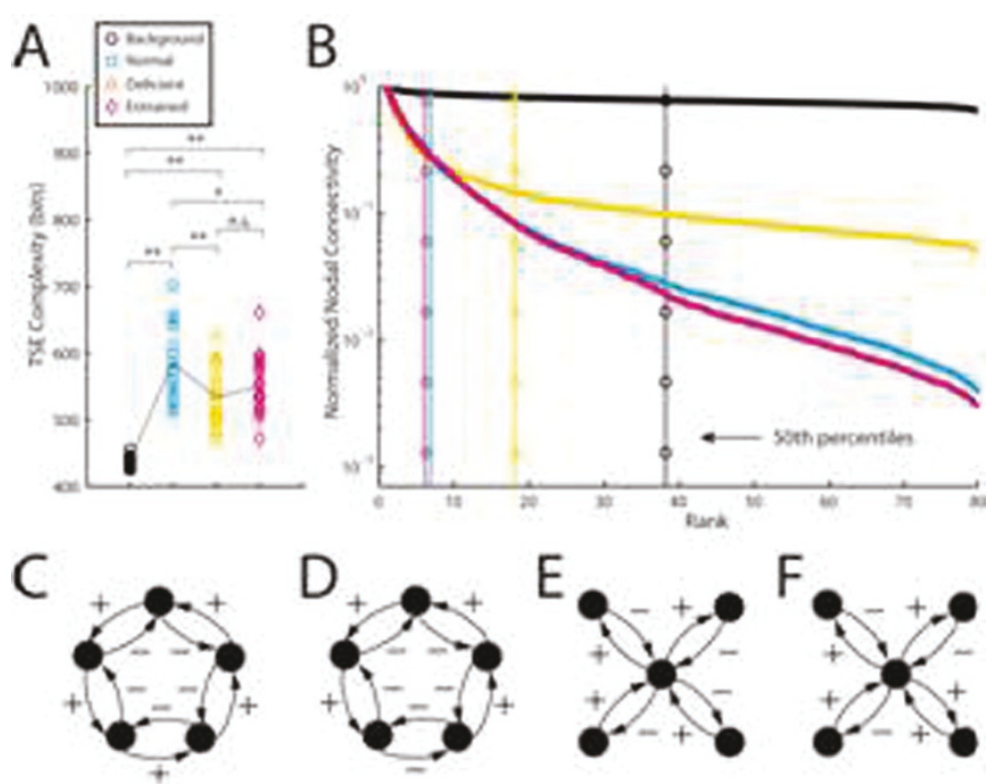

Figure 1 Structural properties of virtual brains from four groups with different power spectra (Background: 1/f spectrum; Normal; Deficient: missing high frequency content - putative schizophrenic brain; Entrained: frequency bands are rational multiples of each other - putative schizophrenic brain). A) Neural complexity is significantly reduced in groups modeling pathological cases. B) Ranking of nodes according to their connectivity reveals a hierarchical brain organization that is less pronounced in the Deficient group. C) Example of an under-represented motif in both pathological cases, D) of an over-represented motif in the Entrained group, E) of an under-represented motif in the Normal group, and F) of an over-represented motif in the Deficient group.

${ }^{3}$ Department of Neurosciences, Case Western Reserve University, Cleveland,

$\mathrm{OH} 44106$, USA

Full list of author information is available at the end of the article 
spindle and sharp waves). We also reverse-engineered putative diseased brains (epileptic and schizophrenic), in which oscillatory activity is altered in different ways [3]. The reconstructed networks show consistent alterations of functional connectivity and dynamics. These alterations lead to a decrease in neural complexity (Fig. 1A), as defined in [4], changes in the hierarchical structure of the brain connectivity (Fig. 1B) and in the probability of finding certain structural motifs (Figs. 1C1D1E1F). The predictions from our model may be easily tested in actual brains.

\section{Acknowledgements}

This work was made possible by the High-Performance Computing Cluster at Case Western Reserve University. We also thank the support from a Choose Ohio First grant (GKS), The Mount Sinai Health Care Foundation (RFG) and The Alfred P. Sloan Foundation (RFG).

\section{Author details}

${ }^{1}$ Department of Biomedical Engineering, Case Western Reserve University, Cleveland, OH 44106, USA. ${ }^{2}$ Currently working at Boston Scientific Neuromodulation, Valencia, CA 91355, USA. '3epartment of Neurosciences, Case Western Reserve University, Cleveland, $\mathrm{OH}$ 44106, USA.

Published: 18 July 2011

\section{References}

1. Buzsaki G: Rhythms of the Brain. Oxford University Press; First 2006.

2. Chu MT, Golub GH: Inverse Eigenvalue Problems: Theory, Algorithms, and Applications. Oxford University Press; 2005.

3. Uhlhaas PJ, Singer W: Neural synchrony in brain disorders: relevance for cognitive dysfunctions and pathophysiology. Neuron 2006, 52(1):155-168.

4. Tononi G, Sporns O, Edelman GM: Measures of degeneracy and redundancy in biological networks. ProcNat/AcadSciUSA 1999, 96(6):3257-3262.

doi:10.1186/1471-2202-12-S1-P108

Cite this article as: Karl Steinke and Galán: Inferring functional brain connectivity from field-potential oscillations in health and disease. BMC Neuroscience 2011 12(Suppl 1):P108.

\section{Submit your next manuscript to BioMed Central} and take full advantage of:

- Convenient online submission

- Thorough peer review

- No space constraints or color figure charges

- Immediate publication on acceptance

- Inclusion in PubMed, CAS, Scopus and Google Scholar

- Research which is freely available for redistribution

Submit your manuscript at www.biomedcentral.com/submit 